\title{
A GIS-based framework of regional irrigation water demand assessment
}

Received: 26 May 2003 / Accepted: 22 December 2003 / Published online: 19 February 2004

(C) Springer-Verlag 2004

\begin{abstract}
Although a lot of research has been performed on estimating irrigation water demand at the on-farm level, far less has been done on irrigation water demand for a region-wide basis, such as for a river basin or an area covering multiple river basins. The capture and management of the spatial variations in related data such as soil, climate, crops, and canal networks is the key to effective and efficient regional irrigation water demand estimations. The Geographic Information System (GIS), with its powerful spatial data management and analysis capabilities is used in this study to extend the scope of on-farm irrigation water estimation into a regional estimation. A command area covering several river basins in southern Taiwan was used to build a model prototype. The model framework shows the capability of the system to estimate regional irrigation water demand with most of the spatial variations preserved. The model also shows the capability for quickly reflecting changes in irrigation water demand in response to changes in cropping patterns, a feature that may be a necessary for regional water resource planning.
\end{abstract}

Keywords Irrigation water demand planning . Geographic Information System - Regional irrigation planning $\cdot$ Cropping patterns $\cdot$ Agriculture

\section{Introduction}

Many areas around the world suffer from a shortage of water due to the rapid growth of population, and/or commercial and industrial activities. In most of the developing countries, the agricultural sector usually holds

\footnotetext{
T.-H. Wen · M.-D. Su (

Department of Bioenvironmental Systems Engineering, National Taiwan University,

10617 Taipei, Taiwan

e-mail: sumd@ccms.ntu.edu.tw

Y.-L. Yeh

Department of Civil Engineering,

National Ping-Tung University of Science and Technology, 80916 PingTung, Taiwan
}

the largest share of the water rights and becomes the target of other sectors when it comes to the issue of regional water supply reallocation. Irrigation consumes or depletes over $70 \%$ of the world's total water supplies (Seckler et al. 1999). The estimation of regional irrigation water demand becomes more and more important in such circumstances. Enormous amounts of knowledge can be extracted from the literature regarding the estimation of on-farm evapotranspiration (ET) for crops. The agricultural research community has focused much on the agronomic side of water use, which is reflected in the very large body of ET literature (Gutwein 1991). Most of this research concentrates on finding the water requirements for different crops under certain field conditions related to soil, climate, and the groundwater table.

Less work has been done in the area of regional irrigation water demand estimation. For large-scale irrigation planning practices, regional irrigation water demand is usually estimated from multiplying the irrigated area by the irrigation demand per unit area. There is actually a huge amount of data involved in estimating regional irrigation water demand, such as the soil, crop, climate, and water distribution infrastructures, and management practices. Most of these related data are spatially distributed. Since these spatial complexities are very difficult to handle, they are usually combined into aggregated forms. Traditionally, irrigation water demand estimations have had to assume a particular soil type for each crop due to a lack of data (Knox et al. 1996). Average soil characteristics were used regardless of any non-uniform field soil distribution.

There are several on-farm irrigation requirement estimation models available. For example, the Irrigation Water Requirements program, which was designed by the USDA-Natural Resources Conservation Service (NRCS), can be used for computing monthly and seasonal irrigation water requirements (Dalton 2000). But the program cannot calculate irrigation requirements for more than one crop at a time, and only one surface soil type can be set up for crop coefficient computations. Therefore, this kind of on-farm irrigation estimation program is not suitable for 
large-scale irrigation planning due to its ignorance of spatial variations in cropping patterns and soil types. Indeed, the major difference between on-farm irrigation estimation models and regional ones is the capability of handling spatial variations. Because there were no suitable tools for handling the spatial complexities of soil, crops, and climate in the past, it was thought that the small-scale physical processes described by the sophistical ET equations were point measures that could not be scaled-up (Morton 1983).

Because of the ignorance of the spatial distribution, the impacts of the spatial variations of related parameters on the regional irrigation water demand are not clearly identified. Decisions based on these traditional "lump estimation" models may lead to inadequate water system planning. Herrero et al. (1999) thought that the prediction of irrigation water volumes needs advanced tools of crop area estimation that combine a ground survey with satellite data to produce statistics of crop areas. Therefore, a spatial approach is particularly appropriate (Knox and Weatherhead 1999). The Geographic Information System (GIS) is the most efficient tool used for spatial data management and utilization that can allow us to improve our understanding of the spatial variance. A GIS-based approach to demand modelling allows us to consider local variations in cropping, soils, and climate, and so facilitates the production of irrigation demand maps (Weatherhead and Knox 1999).

Over the last decade, GIS-based irrigation water mapping techniques have been the subject of widespread discussion. Madsen and Holst (1990) discussed a nationwide mapping of irrigation need based on computerized soil and climate data. By dividing Denmark into four climatic zones and deriving the relationships between the mean irrigation needs and the root zone water holding capacities, maps in grid format for each crop (grass and barley) were produced displaying mean irrigation needs. Although actual land use patterns were not considered, this was a pilot research project to identify where and how much water will be required. Knox et al. $(1996,1997)$ and Knox and Weatherhead 1999) developed the methodology to calculate volumetric irrigation requirement for main crop categories and predict the future growth for irrigation water demand in England and Wales with GIS technology. They used a daily water balance irrigationscheduling model to determine annual irrigation needs for eight crop categories grown on three contrasting soil types at 11 weather stations. Irrigation requirement maps in grid format were then produced.

Although these studies modeled regional irrigation water demand spatially, grid-based maps were used. Gridbased data modeling may be inefficient and inadequate for water resources planning and management. Gridbased datasets are good at representing and displaying information for areas with natural boundaries, such as soil textures and climate conditions. Regional irrigation water demand estimations are usually based on land use or cropping patterns, which have clear artificial boundaries. Therefore a regional irrigation water demand model using a vector-based data model is proposed in this paper. Unlike the studies mentioned above, the proposed GISbased irrigation water demand model is not only for mapping the irrigation demands; it also provides the ability to accurately capture spatial variations and quickly reflect changes in irrigation water demand in response to changes in cropping patterns.

\section{Pilot study area}

As a pilot study, the command area of the Chia-Nan Irrigation Association of Taiwan, which covers three river basins, with two major reservoirs and several river diversions (as shown in Fig. 1) is used in this study. The whole irrigated area, of approximately 78,000 hectares, is divided into seven management subdivisions. Each subdivision consists of several workstations, and each workstation is further divided into several irrigation groups. An irrigation group, made up of 3-5 rotational units with an area of approximately 50 hectares, is the basic irrigation management unit for this irrigation association (Chia-Nan Irrigation Association 2003). The term "rotational unit" comes from the cropping pattern. Paddy rice is the traditional cash crop in Taiwan. A cropping pattern with paddy rice and other crops like soybean, corn and sorghum, rotating each year between these rotational units within an irrigation group, is adopted in the study area because of the shortage of water supply for all-paddy cropping.
Fig. 1 Study area - ChiaNan Irrigation Association in Taiwan

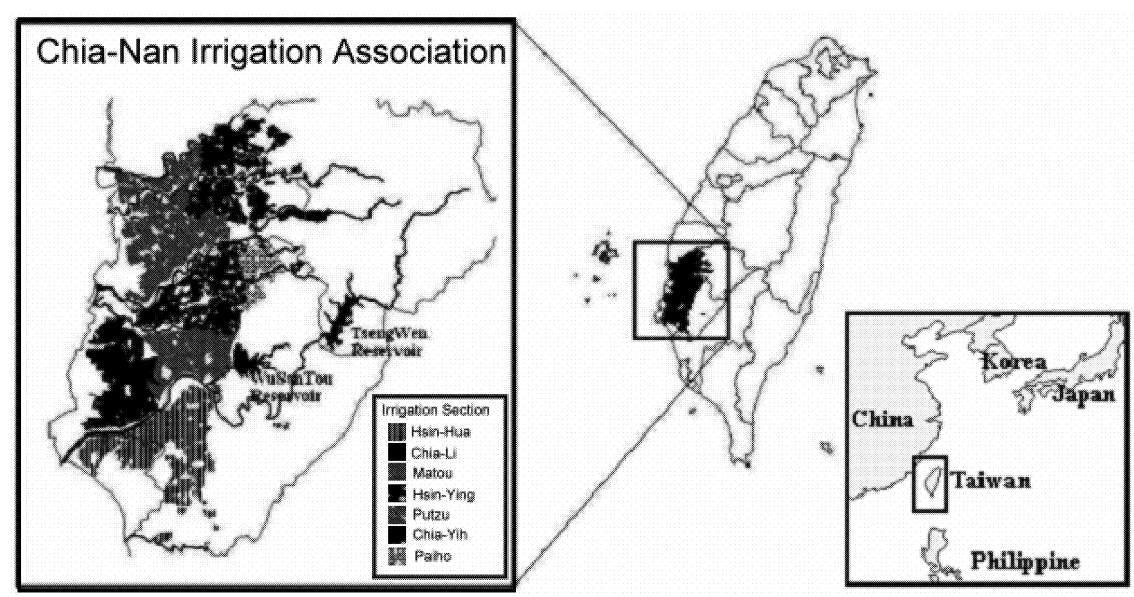




\section{Spatial database}

The on farm irrigation water requirements are the basis for the regional irrigation water demand estimations. In this model, the on-farm crop water requirements are calculated following the most commonly used general routine. ET estimation equations, such as Penman and Blaney-Criddle, are used with the related climate data and crop coefficients for on-farm ET requirement determinations. The rotational unit, with an area of 50 hectares, is used as the basic unit in the model. Basic data for the estimation of irrigation water demand were collected with this spatial resolution. The spatially-variant data, such as climate, crops, soil, and distribution of the canal network, are organized into a form of spatial database.

\section{Climate}

Forty years of daily weather data (such as temperature, precipitation, humidity, wind, solar radiation, and so on) were collected, and climate zoning maps based on ET estimations were generated from a previous study, as shown in Fig. 2 (Hung et al. 1998). Each zone in Fig. 2 is assumed to have the same evapotranspiration characteristics. The climate data, such as temperature, precipitation, and humidity, were also analyzed in the previous study, and statistics with different probabilities of occurrence were generated in 5\% increments for planning purposes. These statistics are built into the model in this study, ready to use to set up a climate scenario needed for regional water demand planning.

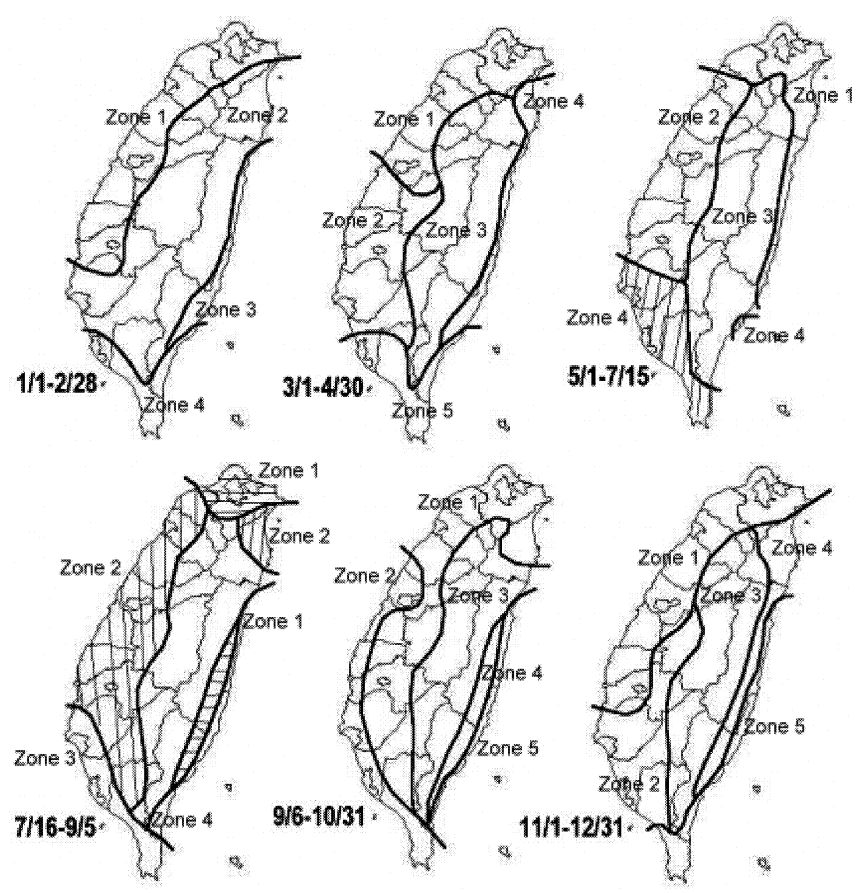

Fig. 2 Zones with the same ET characteristics in different periods

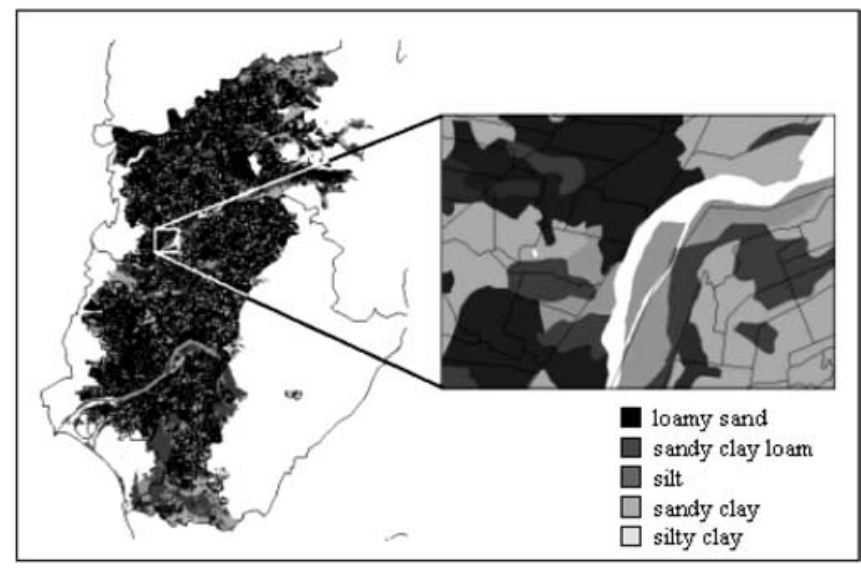

Fig. 3 Variations of top soil texture within rotational unit

\section{Cropping pattern}

Cropping patterns for each rotational unit were built into the geographic database in the model with all of the necessary parameters, such as crop coefficients $\left(K_{c}\right)$ for ET estimations. There are basically four major kinds of cropping pattern in this command area: two paddy crops every year, a single paddy crop every year, two paddy crops every three years, and a single paddy crop every three years. When a farm is not on paddy crop shift, other crops like corn, soybean, sorghum, and sugar cane are cultivated. In this model, ten days is used for a temporal unit; each rotational unit could be set to a different crop category with a different time period according to its cropping pattern. Therefore, users can easily set up the cropping pattern they require with the aid of maps and graphic user interfaces.

\section{Soil}

The soil characteristics are important factors for irrigation demand estimation. For example, the soil intake rate influences the irrigation application efficiency and conveyance efficiency, so the gross water demand for the region may be affected in consequence. The natural variation in soil characteristics does not usually follow the man-made administration boundary. Figure 3 shows the topsoil texture variations within and among rotational units. Since the rotational unit is the basic operational unit of this model, the soil characteristic of each rotational unit is computed by taking the weighted average of the area of each soil type present.

\section{Canal network}

To estimate regional irrigation water demand, the conveyance loss must be added to the on-farm irrigation requirement. The water conveyance loss depends on the canal construction material, maintenance conditions and 
Fig. 4 Geographic database for canal network

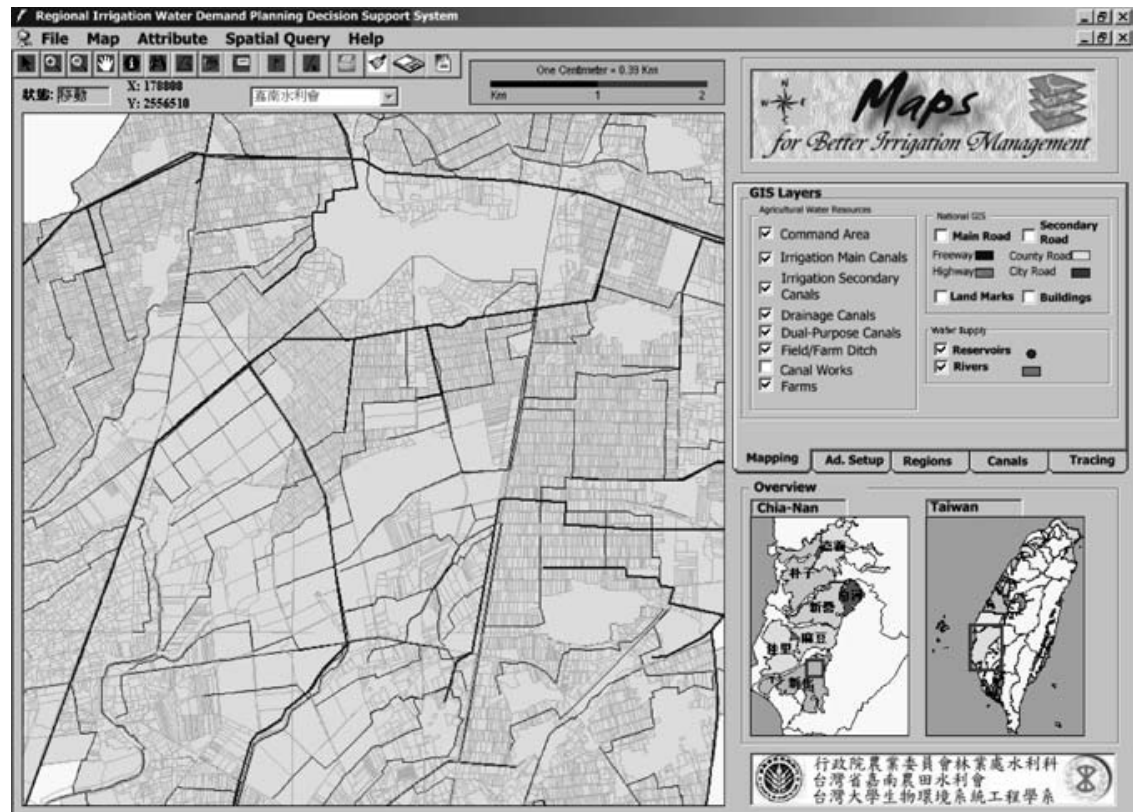

Fig. 5 Geographic database for farms

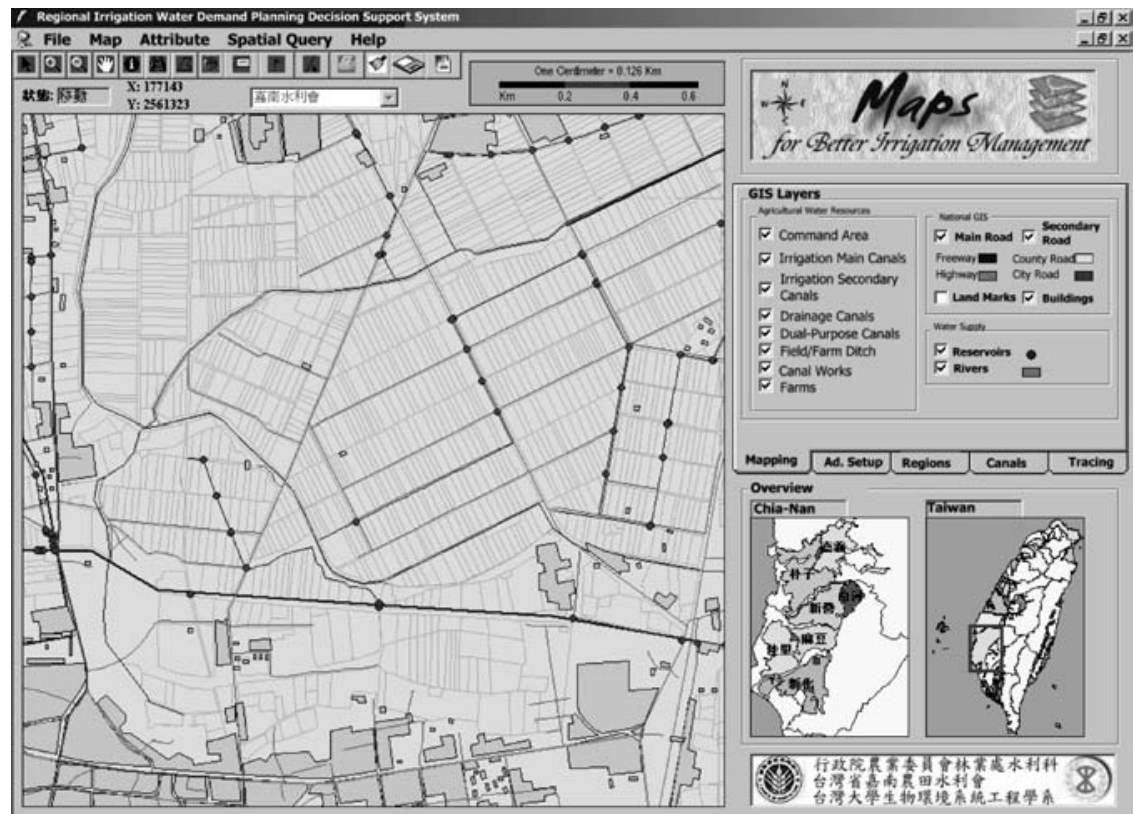

management practices. The main, secondary, sub-secondary and some of the tertiary canals in the study command area are furnished with concrete lining. An irrigation canal network as shown in Fig. 4 was established for the estimate of conveyance loss for the region. A structured coding system was created in this study for numbering each canal section, so that the upstream canal lengths of different canal types, such as lined or unlined, for each rotational unit can be determined. In the model, conveyance losses were estimated from the canal types and field survey data collected from the irrigation association administration.

\section{Command area}

The average farm size in Taiwan is about 0.7 hectares. These farms are grouped into irrigation groups of approximately 150 hectares, which is the basic unit for irrigation management. There are irrigation groups in total in this command area (Chia-Nan Irrigation Association). The spatial database for farms is also established (as shown in Fig. 5) in this study with detailed attribute data such as ownerships, irrigation fee collection data, and productivity grads. These related data may be useful for evaluating social or economic impacts of 


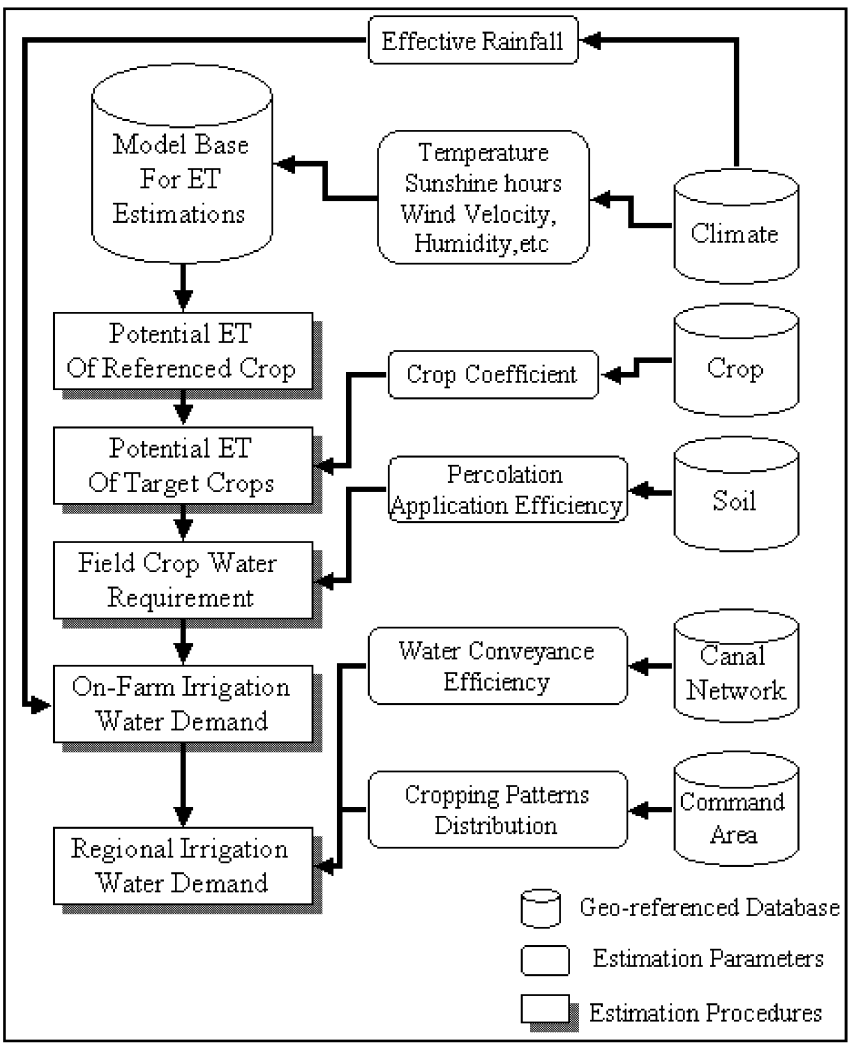

Fig. 6 Regional irrigation water demand estimation framework

policy changes. For example, other than the total affected area, the total numbers of affected farming households can be an important judgment factor for fallow area setups.
Model framework

The proposed model framework for this GIS approach to regional irrigation water demand estimation is shown in Fig. 6. On-farm crop water requirements are first computed for each rotational unit via an ET estimation method chosen by users from the model base. The model base currently contains three commonly used ET estimation methods: FAO Modified Blaney-Criddle, Thornthwaite, and Penman-Monteith. Since there are many empirical ET estimation methods, an interface is also provided in the model for the user to include other ET estimation equations of his choice. A ten day interval is used in this study. Climate statistics and probabilities, chosen by the user, are used to compute the potential ET for each rotational unit. Crop coefficients are then introduced to convert the potential ET to an actual one for the target crop. The on-farm irrigation water demand is generated after the adjustments for irrigation application loss and effective rainfall. The conveyance losses can be estimated using the canal network spatial database. The regional irrigation water demands can then be estimated without losing the spatial variation (unlike some of the old "lump models" did). The estimated irrigation water demand can be presented in various forms such as by administration regions, by cropping patterns, by canal systems, or by water supply sources. With this information, the system manager can not only get improved estimates of the regional irrigation water demands, but he can also better understand the spatial distribution of these water demands in his command area, which should help him improve irrigation planning and management practices.

A prototype of the model was constructed for the study area in this pilot study. The model was built for the Microsoft Windows environment. Microsoft Visual Basic was used as the basic programming language tool for this
Fig. 7 Graphic user interface of the model

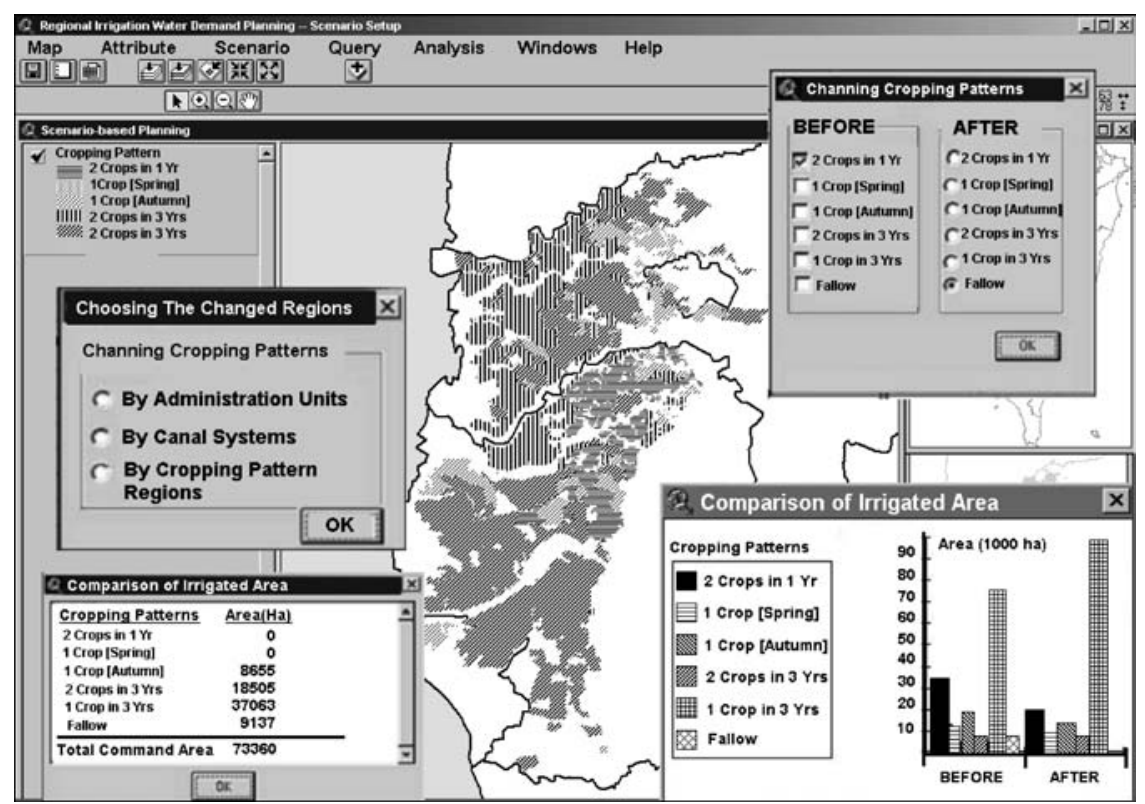


Fig. 8 Sample model output

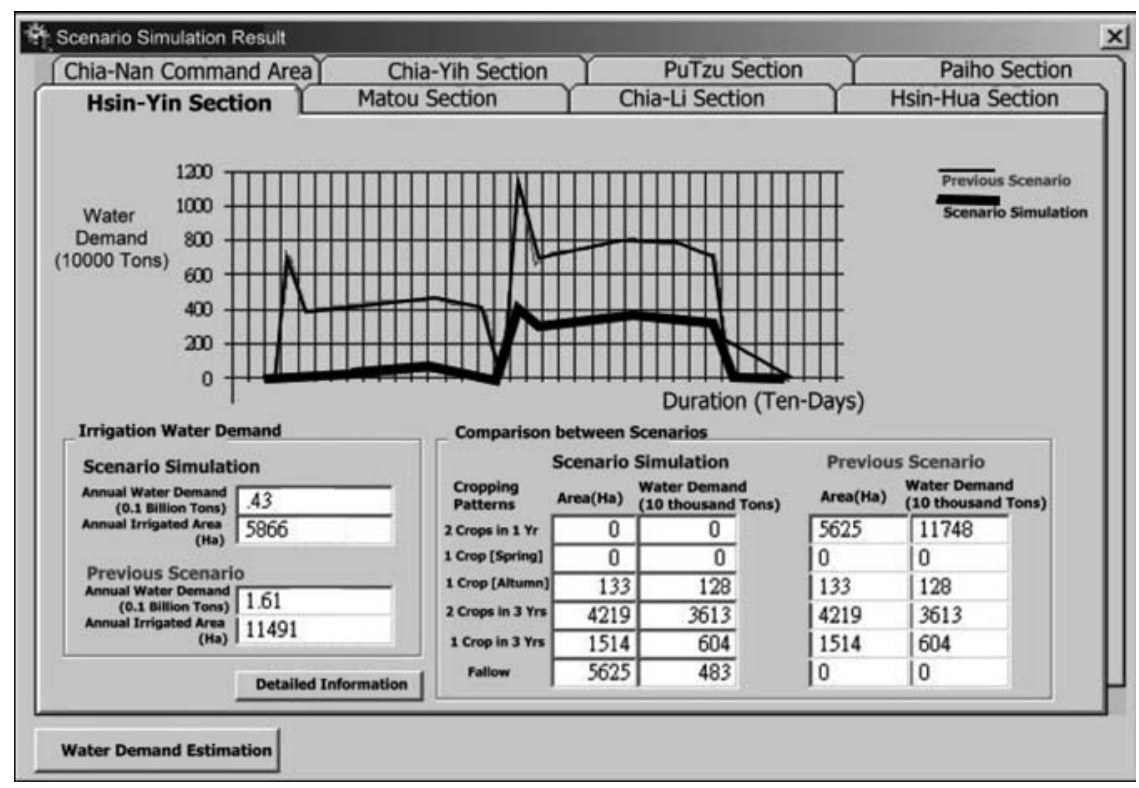

system implementation. MapObjects, a GIS component from the Environmental System Research Institute (ESRI), was used in the system for spatial database handling and management. Friendly graphical user interfaces (as shown in Fig. 7) have been created for manipulating the spatial database, such as adjustment of the cropping patterns or changing the probability distribution for the climate statistics. A sample model output is shown in Fig. 8. The curve shows the irrigation water demand for paddy and other crops in ten day intervals. There are different tabs for demand reports for each subdivision. Related information, such as areas of each crop, is also shown. Tables showing detailed demand distributions plotted with ten day intervals will pop up at the user's command.

\section{Results and discussion}

A GIS approach is used in this study to take into account the spatial variations of data related to regional irrigation demand estimations. Although a traditional database management system can do the same job, GIS creates a better working environment for visual representations and an easier scenario setup with a spatial data display and handling capability (Wen and Su 2002). With its spatial analysis power, this GIS approach can easily arrange the results of regional irrigation water demands into different aggregations, such as by different canal systems, administration areas, or water supply sources. Collecting data for these different aggregations may result in more effective decisions for regional irrigation demand planning and management.

This model framework can be extended to implement a decision support system for regional demand planning. A Decision Support System (DSS) is a tool that enables the decision makers to investigate the influence of factors or decision alternatives (Su and Wen 2001). With all of the related data and models built in, it will be an efficient tool for improving demand planning by setting up different scenarios and revealing the impacts under those scenarios. An application example of this model as a DSS for regional irrigation demand planning is to use thedrought scenario. If the water supply is expected to be reduced by $40 \%$ in an dry year, the Irrigation Association Administration can run this demand estimation model for several

Table 1 Summary of results for demonstrated models

\begin{tabular}{|c|c|c|c|c|c|c|}
\hline \multirow[t]{2}{*}{ Cropping Pattern } & \multicolumn{2}{|l|}{ Current } & \multicolumn{2}{|c|}{ Scenario $\mathrm{A}^{\mathrm{a}}$} & \multicolumn{2}{|c|}{ Scenario $\mathrm{B}^{\mathrm{b}}$} \\
\hline & Area (ha) & $\begin{array}{l}\text { Water demand } \\
\left(1 \times 10^{8} \text { tons }\right)\end{array}$ & Area (ha) & $\begin{array}{l}\text { Water demand } \\
\left(1 \times 10^{8} \text { tons }\right)\end{array}$ & Area (ha) & $\begin{array}{l}\text { Water demand } \\
\left(1 \times 10^{8} \text { tons }\right)\end{array}$ \\
\hline Two paddy crops every year & 9137 & 2.05 & 9137 & 2.05 & 6282 & 1.43 \\
\hline Single paddy crop every year & 8665 & 1.05 & 8541 & 1.02 & 8665 & 1.05 \\
\hline Two paddy crops every three years & 18801 & 1.86 & 18801 & 1.86 & 18801 & 1.86 \\
\hline Single paddy crop every three years & 37063 & 2.06 & 30373 & 1.67 & 37063 & 2.06 \\
\hline Fallow & 0 & 0 & 6814 & 0 & 2855 & 0 \\
\hline Total irrigated area & 73666 & 7.02 & 66852 & 6.6 & 70811 & 6.4 \\
\hline Reduction in water demand $(\%)$ & - & - & - & $6 \%$ & - & $8.8 \%$ \\
\hline
\end{tabular}

\footnotetext{
${ }^{\mathrm{a}}$ Scenario A: put the area with mostly sandy soil into fallow; ${ }^{\mathrm{b}}$ scenario B: put the area with two paddy crops every year into fallow
} 
scenarios of different cropping patterns to search for the one with the least negative impact. The manager may try to shut down a specific canal system with poor maintenance, put a sub-division or a workstation with coarser soil texture into a fallow state to save water loss to deep percolation, or simply reduce the paddy area for less irrigation demand. The model can then readily re-compute the regional irrigation water demand for those scenarios and display related impact information useful for making the final decision. Candidates for this impact information are the paddy area or yield, the area in a fallow state, and the number of affected farms.

As an example, say the regional irrigation water supply is expected to be reduced by $10 \%$ in a drought year. Facing this challenge, the system manager comes up with two candidate solutions. Scenario A is to put the area with mostly sandy soil into fallow, while scenario B is to change the area with two paddy crops every year into a fallow state. Using our DSS, both scenarios can be easily constructed, and the regional irrigation demand can be rapidly estimated. Indeed, the results for this example are summarized in Table 1. Both alternatives would cut down the regional irrigation water demand significantly. But scenario B may be the one chosen because the affected area for this scenario is less than half that affected by scenario $\mathrm{A}$, and the reduction in water demand is slightly larger too. This simple example shows what this spatial model can do to help the decision maker. A crop yield model, where we can take economics into account by estimating the crop yields for different scenarios, could be a potential improvement for this DSS.

\section{Conclusions}

A GIS approach to capturing spatially-distributed data, useful for regional irrigation water demand estimations, is presented in this study. With the built-in spatial database and the graphical user interfaces for spatial data manipulation and scenario setup, this model framework can quickly provide planners with irrigation water demand estimations and other related information for different planning models. More effective decisions on regional irrigation water demand planning can be made based on this supporting information.
Acknowledgements This research was made possible by the fund from the Council of Agriculture of Taiwan under contract 89-AST1.5-FOD-62(5-5). The authors would also like to acknowledge the support from the Chianan Irrigation Association of Taiwan for providing field data and suggestions on model framework implementation.

\section{References}

Chia-Nan Irrigation Association (2003) Homepage. http:// www.chianan.gov.tw/ (cited 9 February 2004)

Dalton JC (2000) Irrigation water requirements. USDA-NRCS User Manual. USDA-NRCS, Washington DC, pp.5-8

Herrero J, Casterad MA (1999) Using satellite and other data to estimate the annual water demand of an irrigation district. Environmental Monitoring and Assessment 55, pp.305-317

Hung YL, Su MD, Yeh YL (1998) Climate zoning for Taiwan based on irrigation demand (in Chinese with English abstract). Taiwan Water Conservancy 46(3), pp.35-49

Gutwein BJ (1991) Analysis and prediction of regional irrigation water demand. PhD Dissertation, Colorado State University, Fort Collins, CO, pp.6-35

Knox JW, Weatherhead EK (1999) The application of GIS to irrigation water resources management in England and Wales. Geographical Journal 165(1), pp.90-98

Knox JW, Weatherhead EK, Bradley RI (1996) Mapping the spatial distribution of volumetric irrigation water requirements for main-crop potatoes in England and Wales. Agricultural Water Management 31, pp.1-15

Knox JW, Weatherhead EK, Bradley RI (1997) Mapping the total volumetric irrigation water requirements in England and Wales. Agricultural Water Management 33, pp.1-18

Madsen HB, Holst KA (1990) Mapping of irrigation need based on computerized soil and climate data. Agricultural Water Management 17, pp.391-407

Morton FI (1983) Operational estimates of areal evaportranspiraiton and their significance to science and practice of hydrology. Journal of Hydrology 66, pp.1-76

Seckler D, Molden D, Barker R (1999) Water scarcity in the twenty-first century. International Water Management Institute, Sri Lanka 1, pp.2-11

Su MD, Wen TH (2001) Decision support systems for irrigation water demand planning. In Proceedings of the World Water and Environmental Resources Congress, 21-24 May 2001, Orlando, FL, p.11 (Electronic Media)

Weatherhead EK, Knox JW (1999) Predicting and mapping the future demand for irrigation water in England and Wales. Agricultural Water Management 43, pp.203-218

Wen TH, Su MD (2002) An integrated spatial-scenario based framework for regional water resources planning. In Proceedings of EWRSA Symposium, 19-22 May 2002, Roanoke, VI, p.10 (Electronic Media) 